\section{Occupational health and safety and} the National Public Health Institute of South Africa: Deliberations from a national consultative meeting

To the Editor: On 11 November 2015, the National Department of Health $(\mathrm{NDoH})$ published the National Public Health Institute of South Africa (NAPHISA) Draft Bill 2015 for public comment. The aim of the Draft Bill is:

' $[\mathrm{t}$ ] o provide for the establishment of the National Public Health Institute of South Africa in order to conduct disease and injury surveillance and to provide specialised public health services, public health interventions, training and research directed towards the major health challenges affecting the population of the Republic.'[1]

The Draft Bill makes provision for four divisions: (i) communicable diseases; (ii) non-communicable diseases; (iii) cancer surveillance; and (iv) injury and violence prevention. No explicit provision related to occupational health $(\mathrm{OH})$ or environmental health $(\mathrm{EH})$ has been made in the Bill. Through the leadership of the $\mathrm{NDoH}$, a consultative meeting was held on 3 February 2016 with occupational health and safety (OHS) experts from across the country, representatives of various economic sectors, academic institutions, professional associations and government departments. The aim of the meeting was: (i) to discuss an OHS system model for South Africa (SA), including that of SA's National Institute for Occupational Health (NIOH); and (ii) to consult on the establishment of the NAPHISA and the role of $\mathrm{OH}$. The $\mathrm{NIOH}$ is currently one of a number of national institutes located under the National Health Laboratory Service. It provides a national expert resource in $\mathrm{OH}$ for the country. However, although initially envisaged for inclusion in NAPHISA in earlier drafts, the NIOH is conspicuously absent from the current draft bill on NAPHISA. Two options for OHS open to the $\mathrm{NDoH}$ were presented for formal consideration at the meeting. One option was for the establishment of an 'occupational health cluster', which may or may not be directly under the administration of the NDoH. The cluster option proposes a merger of the Medical Bureau for Occupational Diseases and the NIOH. The second option proposed was for the explicit inclusion of OHS within the NAPHISA, with an option to expand its ambit to include EH. This second option is supported for a number of reasons: ( $i$ ) environmental and occupational risk factors contribute significantly to the national burden of disease; ${ }^{[2]}$ (ii) an NIOH should service all sectors of the economy, is multidisciplinary by nature, predominantly addresses prevention, while having a referral clinical service role, and must be involved in cross-departmental collaboration to ensure policy alignment and coherent service delivery; (iii) international best practice confirms the place of $\mathrm{OH}$ and $\mathrm{EH}$ as a component of public health institutes; ${ }^{[3]}$ (iv) SA's recent ratification of the International Covenant on Economic, Social and Cultural Rights imposes on government obligations related to $\mathrm{OH}$ and $\mathrm{EH}$ as a component of the right to health; ${ }^{[4]}$ and $(v)$ OHS is a subdiscipline of public health, and its exclusion from a national public health institute would be artificial and hamstring efforts to intervene effectively in workers' and population health. The ideal functions of a public health institute that delivers OHS services were also discussed and are summarised in Table 1.

In the absence of a national OHS and EH policy framework and given the current fragmentation of services, there was a strong argument presented that in order to fulfil these national functions OHS and EH would be better placed within an independent publicly funded institute with oversight by key stakeholders rather than through an 'occupational health cluster' model. Given the current policy moment, it would appear to be rational to make explicit

Table 1. Ideal functions of a National Public Health Institute delivering OHS services

\begin{tabular}{|c|c|}
\hline Function & Rationale \\
\hline 1. Surveillance & $\begin{array}{l}\text { Need for an institute to identify, validate and analyse routinely collected data on occupational exposures, disease and } \\
\text { injury frequencies as well as mortality. Identify surveillance data gaps and improve the completeness and accuracy of data. }\end{array}$ \\
\hline 2. Priority identification & $\begin{array}{l}\text { Informed by research and analysis of surveillance data, priority areas within OHS safety are identified with a } \\
\text { focus on prevention and vulnerable groups. }\end{array}$ \\
\hline 3. Evidence-informed policy & Provide context- and policy-relevant information to policy makers to ensure that OHS policy is scientifically sound. \\
\hline $\begin{array}{l}\text { 4. Specialised occupational } \\
\text { health services }\end{array}$ & $\begin{array}{l}\text { Provide specialist services in occupational medicine, hygiene, toxicology, immunology, microbiology, pathology } \\
\text { and other relevant disciplines. }\end{array}$ \\
\hline 5. Monitoring and evaluation & $\begin{array}{l}\text { Develop OHS indicators to monitor trends and assess the effectiveness of OHS interventions. Continuous } \\
\text { engagement with policy makers to communicate progress toward policy objectives. }\end{array}$ \\
\hline 6. Advisory services & $\begin{array}{l}\text { Consultations to provide an independent source of expertise for the state, practitioners, scientists, trade unions, } \\
\text { enterprises and the public. }\end{array}$ \\
\hline $\begin{array}{l}\text { 7. Clinical and occupational } \\
\text { hygiene practice guidelines }\end{array}$ & Develop and communicate clinical and occupational hygiene guidelines to service providers. \\
\hline 8. Information & $\begin{array}{l}\text { Provide unbiased scientifically sound information to practitioners, employers, employees and the public on } \\
\text { OHS-related matters. }\end{array}$ \\
\hline 9. International best practice & $\begin{array}{l}\text { Develop and maintain partnerships with similar institutes in other countries as well as multilateral organisations } \\
\text { to ensure and inform international best practice in OHS. }\end{array}$ \\
\hline 10. Training & $\begin{array}{l}\text { Engage with academia and inform OHS training curricula to ensure that appropriate skills are acquired by future } \\
\text { OH practitioners. Provide training on specific aspects not provided for elsewhere. }\end{array}$ \\
\hline $\begin{array}{l}\text { 11. Reference laboratory of } \\
\text { OEH }\end{array}$ & Act as a national reference laboratory for $\mathrm{OH}$ and $\mathrm{EH}$. \\
\hline 12. Research & nduct and facilitate context-specific research in OHS. \\
\hline
\end{tabular}


provision for OHS as well as EH within NAPHISA. A reference group was established at the conclusion of the meeting and tasked to consolidate views from the meeting into a formal submission to inform revisions on the NAPHISA Draft Bill. It is important that SA seizes this important policy moment to establish sustainable plans and systems that will respect, protect, fulfil and promote workers' rights to OHS and the population's right to live in a health-promoting environment.

J E Myers, L London, School of Public Health and Family Medicine, Faculty of Health Sciences, University of Cape Town, South Africa; C Badenhorst, National Office, Southern African Institute for Occupational Hygiene, Midrand, Gauteng, South Africa; M Bida, Division of Anatomical Pathology, School of Pathology and PreClinical Sciences, Sefako Makgatho Health Sciences University, Pretoria, South Africa; S Carstens, Division of Community Health, Faculty of Medicine and Health Sciences, Stellenbosch University, Tygerberg, Cape Town, South Africa; K Davies, National Office, South African Society of Occupational Health Nursing Practitioners, East Rand, Gauteng, South Africa; F Fox, National Office, South African Society for Occupational Medicine, Pretoria, South Africa; F Hyera, Department of Public Health Medicine, School of Health Sciences, University of Limpopo, South Africa; M Jeebhay, School of Public Health and Family Medicine, Faculty of Health Sciences, University of Cape Town, South Africa; R N Naidoo, School of Nursing and
Public Health, College of Health Sciences, Nelson R Mandela School of Medicine, University of KwaZulu-Natal, Durban, South Africa; G Reagon, School of Public Health, Faculty of Community and Health Sciences, University of the Western Cape, Cape Town, South Africa; A Rose, Department of Community Health, Faculty of Health Sciences, University of the Free State, Bloemfontein, South Africa; B Walters-Girout, National Office, South African Society of Occupational Health Nursing Practitioners, East Rand, Gauteng, South Africa; K Voyi, School of Health Systems and Public Health, Faculty of Health Sciences, University of Pretoria, South Africa; Z Vundle, Department of Public Health, Faculty of Health Sciences, Walter Sisulu University, Mthatha, Eastern Cape, South Africa; L Rispel, School of Public Health, Faculty of Health Sciences, University of the Witwatersrand, Johannesburg, South Africa

leslie.london@uct.ac.za

1. National Department of Health, South Africa. National Public Health Institutes of South Africa Bill, 2015. http://www.gov.za/sites/www.gov.za/files/39392_gon1092.pdf (accessed 4 February 2016)

2. Forouzanfar $\mathrm{H}$, Alexander MH, Anderson HR, et al. Global, regional, and national comparative risk assessment of 79 behavioural, environmental and occupational, and metabolic risks or clusters of risks in 188 countries, 1990-2013: A systematic analysis for the Global Burden of Disease Study 2013. Lancet 2015;386(10010):2287-2323. DOI:10.1016/S0140-6736(15)00128-2

3. Framework for the Creation and Development of National Public Health Institutes, 2007. http://www. ianphi.org/documents/pdfs/frameworkfornphi (accessed 11 February 2016).

4. International Covenant on Economic Social and Cultural rights, 1996. http://www.ohchr.org/ International Covenant on Economic Social and Cultural rights,
Documents/ProfessionalInterest/cescr.pdf (accessed 22 February 2016).

S Afr Med J 2016;106(6):538-539. DOI:10.7196/SAMJ.2016v106i6.10738 